\title{
Rheumatoid arthritis in blacks in South Africa
}

\author{
GIRISH M MODY AND ORLANDO L MEYERS
}

From the Rheumatic Diseases Unit, Department of Medicine, Groote Schuur and Princess Alice Orthopaedic Hospitals and University of Cape Iown, Cape Town, South Africa

SUMmARY The spectrum of rheumatoid arthritis (RA) was studied in a group of 52 blacks who attended a rheumatology unit in Cape Town, South Africa. The mean age of the patients was 44.6 years, and the female to male ratio was $3 \cdot 7: 1$. Significant radiographic changes were frequently noted, and the mean Larsen scores were 34.9 for the hands, 19.6 for the feet, and 6.6 for the wrists. About two thirds of the patients had received an immunomodulatory drug and 20 (38\%) had had one or more surgical procedures for their RA. Anaemia was the commonest extra-articular manifestation, and although the other extra-articular features were uncommon, a variety of features had been detected during the course of the disease. Earlier studies on blacks in Africa suggested that RA was a mild disease; our findings, however, are in agreement with the more recent surveys, which suggest that severe disease is not uncommon.

For a long time rheumatoid arthritis (RA) has been recognised as being uncommon in blacks in Africa. Furthermore, there have been marked variations in the spectrum of the disease in studies from Africa which have been reported. ${ }^{1-8}$ Most of the earlier studies emphasised the mildness of the disease in blacks, ${ }^{135}$ but more recent surveys have suggested that the occurrence of severe disease is not uncommon..$^{6-8}$ The only published clinical study of South African blacks with RA was by Anderson in $1970 .{ }^{5}$ He reviewed 23 patients who were seen during a three month period and noted that in blacks RA ran a mild course, tended to remit, deformity was rare, and that the radiological changes were unimpressive. $^{5}$

Epidemiological surveys in South Africa have shown that although the prevalence of RA in an urban black population was similar to that in Caucasians in Europe, ${ }^{9}$ a significantly lower prevalence was noted in rural Tswanas. ${ }^{10}$ The prevalence of RA in urban blacks, ${ }^{9}$ however, did not differ significantly from that in the rural population surveys in the Transkei ${ }^{11}$ and Lesotho. ${ }^{12}$

The aim of this study was to determine the spectrum of RA in blacks who were seen in the rheumatic diseases unit in Cape Town, South Africa.

Accepted for publication 2 June 1988.

Correspondence to Dr Girish M Mody, Department of Medicine, University of Natal, PO Box 17039, Congella 4013, South Africa.

\section{Patients and methods}

All the blacks with classical and definite $\mathrm{RA}^{13}$ who were seen in the rheumatic diseases unit in Cape Town over a 16 month period preceding the study were considered eligible for inclusion in the study. The rheumatic diseases unit of the University of Cape Town conducts an arthritis clinic at the Groote Schuur and Princess Alice Orthopaedic Hospitals. The Groote Schuur Hospital is a large general public hospital and attends to the needs of all the different communities. Patients pay a hospital fee based on their income, and patients are not turned away because of their inability to pay their hospital fees. Patients are referred to the arthritis clinic from other departments in the hospital, by general practitioners, and by primary health care centres. The Princess Alice Orthopaedic Hospital is a specialist hospital, where patients with rheumatological and orthopaedic problems are admitted for control of their disease, rehabilitation, and surgery. Patients are also referred there directly from general practitioners and primary health care centres. Fifty five blacks were seen during the study period, of whom 52 agreed to take part in the study. During this period 203 Caucasians, 330 coloureds (NegroCaucasoids), and 15 Asians with RA were seen in the rheumatic diseases unit. Although blacks constitute the majority population of South Africa, there are a smaller number of blacks in the Cape Peninsula. According to the population census in 1985 the proportion of patients from the different 
communities who were resident in the Cape Peninsula was coloureds $54.3 \%$, Caucasians $28.0 \%$, blacks $16 \cdot 5 \%$, and Asians $1.2 \%$. ${ }^{14}$ Thus the proportion of patients with RA who were seen in the rheumatic diseases unit was roughly proportional to their representation in the local community. Most patients were seen in the unit on a regular basis and most of them belonged to the poorer social classes, in accordance with their distribution in the community.

All the patients were interviewed and the age, duration of RA, and American Rheumatism Association (ARA) functional classification ${ }^{15}$ were recorded. A history of the use of any immunomodulatory drugs and surgery for RA was noted. A history of pain in the various joints was recorded. Patients who did not have pain at the time of assessment but had had pain in a joint at some stage during the course of their disease were considered to have 'past' pain in those joints. If a patient had pain in a joint at the time of assessment they were considered to have 'present' pain, irrespective of whether they had had or had not had pain in those joints in the past. The hospital records of the patients were reviewed with particular attention to the presence of any extra-articular manifestations of RA, drug treatment, and surgery.

Standard radiographs of the hands, wrists, and feet were taken and graded according to Larsen's standard radiographs. ${ }^{16}$ Patients who had had surgery to the joints or severe deformities where grading was not possible were excluded from the radiographic analysis. The range of scores for the radiographs was $0-100$ for hands, $0-10$ for wrists, and $0-50$ for feet. A combined score for these joints was obtained by the sum of the score for the hands and feet + (wrist score $\times 5$ ), giving a range of $0-200 .^{17}$

The following tests were performed in all the patients: full blood count (Coulter S-plus automated counter), blood urea, electrolytes, serum creatinine, serum albumin and globulins (Technicon SMAC 12 autoanalyser), serum immunoglobulins (Behring Laser nephelometer), latex test for rheumatoid factor (slide agglutination technique; Ortho Diagnostics), and antinuclear factor (indirect immunofluorescent technique).

\section{Results}

The mean age of the patients at the onset of RA was $\stackrel{\vec{\omega}}{\circ}$ 36.6 years (range 17-54). Table 1 shows the mean age at the time of assessment, the mean duration of $O$ RA, the sex ratio, and the ARA functional classifi- $\stackrel{+}{\infty}$ cation in comparison with other series. Forty four $\overrightarrow{-}$ patients $(85 \%)$ had classical RA and eight patients 8 $(15 \%)$ had definite RA. Forty five patients $(87 \%)$ 을 were outpatients at the time of assessment. The associated diseases which were present were hypertension in $10(19 \%)$, ischaemic heart disease in two $(4 \%)$, asthma in three $(6 \%)$, and previous pulmon- $\frac{\stackrel{\rho}{2}}{2}$ ary tuberculosis in six $(12 \%)$.

Table 2 shows the frequency of pain in the various joints. The most frequent sites of joint pain were the wrists, hands, ankles, shoulders, and knees.

Table 2 Frequency of joint pain

\begin{tabular}{|c|c|c|c|c|}
\hline & Past & Present & Total & $\begin{array}{l}\text { Total } \\
\text { percentage }\end{array}$ \\
\hline Cervical spine & 23 & 22 & 45 & 87 \\
\hline Temporomandibular joints & 24 & 14 & 38 & 73 \\
\hline Shoulders & 19 & 31 & 50 & 96 \\
\hline Elbows & 24 & 23 & 47 & 90 \\
\hline Wrists & 19 & 33 & 52 & 100 \\
\hline Hands & 30 & 22 & 52 & 100 \\
\hline Hips & 14 & 11 & 25 & 48 \\
\hline Knees & 15 & 34 & 49 & 94 \\
\hline Ankles & 23 & 27 & 50 & 96 \\
\hline Mid-foot & 17 & 19 & 36 & 69 \\
\hline Forefoot & 16 & 21 & 37 & 71 \\
\hline
\end{tabular}

Table 1 Comparison of the demographic data and functional classification

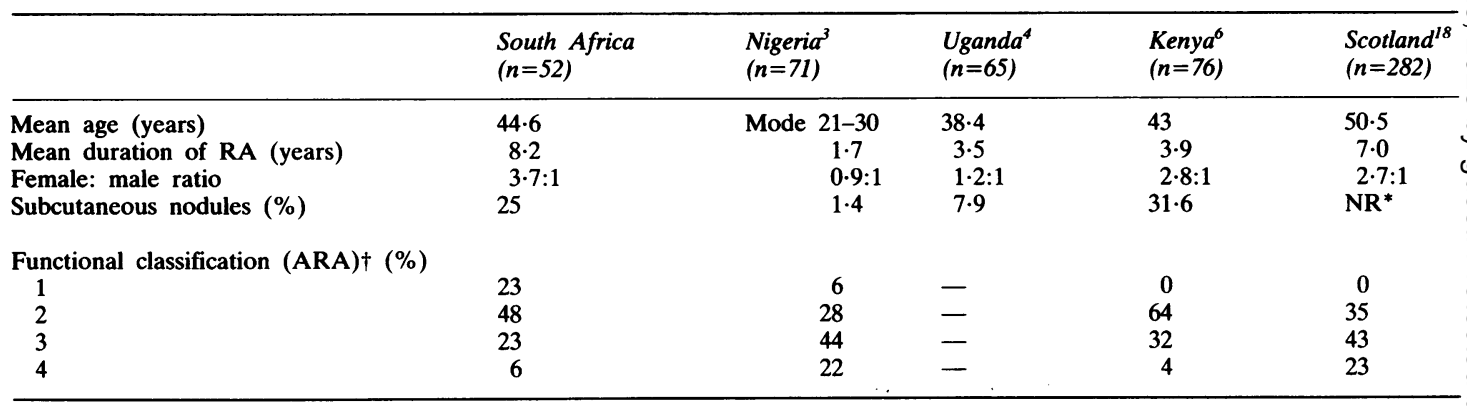

${ }^{*} \mathrm{NR}=$ not reported.

†The proportion of outpatients and hospitalised patients varied in the different series-see text. 
The commonest extra-articular manifestation was the presence of anaemia. Twenty one patients $(40 \%)$ were anaemic at the time of assessment (haemoglobin $<116 \mathrm{~g} / \mathrm{l}$ in women and $<133 \mathrm{~g} / 1$ in men), and a total of 36 patients $(69 \%)$ had anaemia at some stage during their hospital follow up. Subcutaneous nodules were noted in 13 patients $(25 \%)$. Five patients $(10 \%)$ had keratoconjunctivitis sicca and one patient $(2 \%)$ had scleritis and episcleritis. Four patients had pulmonary abnormalities, which had been investigated by the respiratory physicians; one patient had fibrosing alveolitis due to RA, while the others had pneumoconiosis related to occupational exposure. One patient had acute pericarditis, which was attributed to RA after a pericardial biopsy showed no evidence of tuberculosis. Three patients $(6 \%)$ had developed a ruptured Baker's cyst. Two patients had leg ulcers, but one of these was attributed to coexistent varicose veins. The neurological abnormalities which had been recorded were carpal tunnel syndrome (one patient), a mild sensory peripheral neuropathy (one patient), and two patients had a cervical myelopathy (one patient had severe atlantoaxial subluxation and the other cervical spondylosis with subaxial subluxation).

The radiographs of 42 patients were suitable for grading according to the Larsen standard radiographs, ${ }^{16}$ and Table 3 shows the results. Table 4 shows the results of the biochemical and immunological tests. Three patients $(6 \%)$ had a low serum

Table 3 Radiographic findings

\begin{tabular}{lc}
\hline Mean values & $34 \cdot 9$ \\
Hands & $19 \cdot 6$ \\
Feet & $6 \cdot 6$ \\
Wrists & \\
& \\
Range of combined score for hands, wrists and feet \\
Score & $\%$ \\
$0-40$ & $2 \cdot 3$ \\
$41-80$ & $39 \cdot 5$ \\
$81-120$ & $39 \cdot 5$ \\
$121-160$ & $11 \cdot 6$ \\
$161-200$ & $7 \cdot 0$ \\
\hline
\end{tabular}

Table 4 Laboratory findings

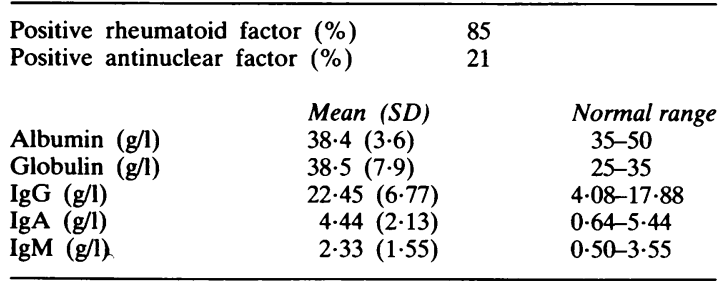

albumin of $<35 \mathrm{~g} / 1$ and 29 patients $(56 \%)$ had raised globulins of $>35 \mathrm{~g} / \mathrm{l}$. Twenty six patients $(50 \%)$ were currently receiving a slow acting antirheumatic or immunomodulatory drug. In addition, a further eight patients $(15 \%)$ had received an immunomodulatory drug in the past. Twenty patients $(38 \%)$ had had one or more surgical procedures for their RA: seven $(13 \%)$ had had only upper limb surgery, 10 $(19 \%)$ had had only lower limb surgery, and three patients $(6 \%)$ had had both upper and lower limb surgery.

\section{Discussion}

Earlier studies of RA in blacks from Africa have emphasised the mildness of the disease, the almost equal male to female distribution, the infrequent findings of subcutaneous nodules, and the lack of extra-articular manifestations. The demographic data, prevalence of nodules, and functional classification of patients in the present survey are compared with some of the other studies from Africa $^{3468}$ and the observations by Duthie $e t$ al in Scotland. ${ }^{18}$ The sex ratio and prevalence of nodules in our patients are similar to the more recent findings in Kenya and Lesotho ${ }^{68}$ and differ from the earlier Nigerian and Ugandan studies. ${ }^{34}$ The results of the ARA functional classification in the different countries in Africa and the Scotland study are not strictly comparable because all the patients in the Scotland series, $70 \%$ from Nigeria, $20 \%$ from Kenya, and only $13 \%$ of our patients were inpatients at the time of assessment.

Table 2 shows the frequency of pain in various joints. It is likely that in some of the patients the pain arose from periarticular structures rather than from the joint itself. The increased prevalence of a positive rheumatoid factor in blacks without RA has been previously reported. ${ }^{819}$ The prevalence of a positive rheumatoid factor and antinuclear factor in our patients with RA is similar to the observation in Caucasians. ${ }^{2022} \mathrm{~A}$ rise in the total serum globulins and IgG, which has been reported in Caucasians, ${ }^{23-25}$ was also noted in this study.

The occurrence of severe erosive changes in blacks was noted in more recent surveys, ${ }^{6-8}$ whereas in earlier studies the disease was considered to be relatively mild. ${ }^{135}$ Scott et al reported the radiographic findings of 56 patients with active RA who were treated with remittive agents. ${ }^{26}$ The mean Larsen score for their patients after 12 months' treatment was 64.8 in comparison with a score of 87.7 for our patients. The mean duration of RA in our patients whose radiographs were analysed was 7.8 years, whereas only $14.2 \%$ of the patients reported by Scott $e t$ al had had their disease for more than five years. ${ }^{26}$ 
Tuberculosis is still very common in South African blacks. Therefore, when patients with RA have lymphadenopathy, pleural or parenchymal involvement of the lung, or pericarditis, they need to be investigated to determine whether these abnormalities are due to RA or to coexistent tuberculosis. The prevalence of nodules in $25 \%$ of our patients is similar to the observations in Kenya and Lesotho $^{68}$ and also to the $20-35 \%$ reported in Caucasians. ${ }^{27}$ Anaemia was the commonest extraarticular manifestation, and its prevalence was similar to observations in Caucasians. ${ }^{28} 29$ The prevalence of the other extra-articular manifestations of RA in our black patients was much less than previously reported by Gordon et $a l^{30}$; the latter survey, however, was undertaken in hospitalised patients, whereas most of our patients were outpatients. A wide spectrum of the extra-articular manifestations of RA was encountered in our patients even though they were uncommon.

Most of the previous surveys on RA were performed in general hospitals, whereas our patients were seen in a rheumatic disease unit which was attached to a large general hospital. There are no previous reports on the frequency of use of immunomodulatory drugs or surgery for RA in blacks in Africa. We found that $34(65 \%)$ of our patients had taken an immunomodulatory drug and $20(38 \%)$ had had one or more surgical procedures for their RA.

\section{References}

1 Hall L. Polyarthritis in Nairobi Africans. East Afr Med J 1963; 40: 354-8.

2 Gelfand M. 'Medical' arthritis in African practice. Cent Afr J Med 1969; 15: 131-5.

3 Greenwood D M. Polyarthritis in Western Nigeria. I. Rheumatoid arthritis. Ann Rheum Dis 1969; 28: 488-96.

4 Kanyerezi B E, Baddeley H, Kisumba D. Rheumatoid arthritis in Ugandan Africans. Ann Rheum Dis 1970; 29: 617-21.

5 Anderson I F. Rheumatoid arthritis in the Bantu. S Afr Med J 1970; 44: 1227-9.

6 Bagg L R, Hansen D P, Lewis C, Houba V. Rheumatoid arthritis in Kenya. I. Clinical observations. Ann Rheum Dis 1979; 38: 23-5.

7 Percy-Lancaster R. Arthritis survey in the Transkei and Ciskei. $S$ Afr Med J 1974; 48: 2355-6.

8 Moolenburgh J D, Moore S, Valkenburg H A, Erasmus M G. Rheumatoid arthritis in Lesotho. Ann Rheum Dis 1984; 43: 40-3.

9 Solomon L, Robin G, Valkenburg H A. Rheumatoid arthritis in an urban South African Negro population. Ann Rheum Dis 1975; 34: 128-35.

10 Beighton P, Solomon L, Valkenburg H A. Rheumatoid arthritis in a rural South African Negro population. Ann Rheum Dis 1975; 34: 136-40.

11 Meyers O L, Daynes G, Beighton P. Rheumatoid arthritis in $\mathrm{a}^{\text {? }}$ tribal Xhosa population in the Transkei, Southern Africa. $A n n ?$ Rheum Dis 1977; 36: 62-5.

12 Moolenburgh J D, Valkenburg H A, Fourie P B. A population study on rheumatoid arthritis in Lesotho, southern Africa. $A n n \overrightarrow{\widetilde{D}}$ Rheum Dis 1986; 45: 691-5.

13 Ropes M W, Bennett G A, Cobb S, Jacox R, Jessar R A. 1958 revision of the diagnostic criteria for rheumatoid arthritis. Bull? Rheum Dis 1958; 9: 175-6.

14 Central Statistical Services. Population census. Age by develop - ment region, statistical region and district. Republic of Southw Africa. Pretoria: Government Printers, 1985. (Report No 02-85-02.)

15 Steinbrocker O, Traeger C H, Batterman R C. Therapeutic criteria in rheumatoid arthritis. JAMA 1949; 140: 659-62. $\frac{\triangleright}{\infty}$

16 Larsen A, Dale K, Eek M. Radiographic evaluation of rheuma-toid arthritis and related conditions by standard reference films. Acta Radiol [Diagn] (Stockh) 1977; 18: 481-91.

17 Larsen A, Dale K. Standardized radiological evaluation of rheumatoid arthritis in therapeutic trials. In: Dumonde D C Jasani J K, eds. Recognition of anti-rheumatic drugs. Lancaster C MTP Press, 1978: 285-92.

18 Duthie J J R, Thompson M, Weir M M, Fletcher W B. MedicaE and social aspects of the treatment of rheumatoid arthritis. Anr Rheum Dis 1955; 14: 133-49.

19 Chalmers I M, Pudifin D J, Shepherd E G. Rheumatoid factor $\overrightarrow{0}$ in non-rheumatoid black patients. $S$ Afr Med J 1977; 51: 617-20

20 Davis J S. Rheumatoid factors. In: Cohen A S, ed. Rheu: matology and immunology. New York: Grune and Stratton 1979: $77-80$.

21 Pollak V E. Anti-nuclear antibodies in families of patients with systemic lupus erythematosus. $N$ Engl J Med 1964; 271: 165-71 Oे

22 Webb J, Whaley K, MacSeen R N M, Nuki G, Dick W CO Buchanan W W. Liver disease in rheumatoid arthritis an Sjögren's syndrome. Prospective study using biochemical and serological markers of hepatic dysfunction. Ann Rheum Di? 1975; 34: 70-81.

23 Cockel R, Kendall M J, Becker J F, Hawkins C F. Serum? biochemical values in rheumatoid disease. Ann Rheum DiS? 1971; 30: 166-70.

24 Tilve G H, Lengade J K, Nair K G, Bavadekar A V, Baxi A J Shah R C. Serum immunoglobulin status in rheumatoig arthritis. J Indian Med Assoc 1977; 69: 25-6.

25 Pruzanski W, Russell M L, Gordon D A, Ogryzlo M A. Seruri: and synovial fluid proteins in rheumatoid arthritis and degenero ative joint disease. Am J Med Sci 1973; 265: 483-90.

26 Scott D L, Dawes P T, Fowler P D, Grindulis K A, Shadfortb $M$, Bacon $P$ A. Anti-rheumatic drugs and joint damage iñ rheumatoid arthritis. $Q J$ Med 1985; 54: 49-59.

27 Harris E D. Rheumatoid arthritis: the clinical spectrum. In음 Kelley W N, Harris E D, Ruddy S, Sledge C B, eds. Textbook of rheumatology. 1st ed. Philadelphia: Saunders, 1981: 928-63 N

28 Mowat A G. Haematological abnormalities in rheumatoid arthritis. Semin Arthritis Rheum 1971; 1: 195-219.

29 Hansen T M, Hansen N E, Birgens H S, Holund B, Lorenzen IN Serum ferritin and the assessment of iron deficiency in rheuma toid arthritis. Scand J Rheumatol 1983; 12: 353-5.

30 Gordon D A, Stein J L, Broder I. The extra-articular features of rheumatoid arthritis. A systematic analysis of 127 cases. Am Med 1973; 84: 445-52. 